Rev. Latinoam. Psicopat. Fund., São Paulo, v. 14, n. 2, p. 237-251, junho 2011

\title{
A repetição e o Projeto de 1895: gérmen de um conceito*
}

\author{
Diego Frichs Antonello \\ Regina Herzog de Oliveira
}

Este artigo tem como propósito trazer uma contribuição à questão da repetição na teoria freudiana. Partindo dos textos pré-psicanalíticos propomos resgatar o conceito de vivência de dor, que nos coloca frente ao problema da repetição do desprazer. A dor aparece como uma falha dos dispositivos de proteção do aparato neuronal, apontando um processo que, mesmo envolvendo o desprazer, continua se repetindo, e nos dá indícios do que será designado, vinte anos depois, como compulsão à repetição.

Palavras-chave: Vivência de dor, repetição, temporalidade, memória

* Este artigo está ligado à pesquisa de Mestrado, em andamento, orientada por Regina Herzog de Oliveira e desenvolvida por Diego Frichs Antonello junto ao Programa de Pós-graduação em Teoria Psicanalítica, Instituto de Psicologia da Universidade Federal do Rio de Janeiro (Rio de Janeiro, RJ, Brasil). Nossa pesquisa conta com o apoio da CAPES - Coordenação de Aperfeiçoamento de Pessoal de Nível Superior (Brasília, DF, Brasil), com bolsa de Mestrado, e do Conselho Nacional de Desenvolvimento Científico e Tecnológico - CNPq (Brasília, DF, Brasil), com bolsa de produtividade em pesquisa. 
O "Projeto para uma psicologia científica" (Freud, 1895[1950]) é uma tentativa de trazer para o plano científico o que se apresentava na clínica pré-psicanalítica em seu início vienense, especialmente nos estudos realizados sobre a histeria. Nesta perturbação psíquica os sintomas se manifestavam, principalmente, sob a forma de ideias excessivamente intensas "nas quais (...) a característica quantitativa emerge com mais clareza do que seria normal" (p. 347).

A época que antecede a escrita do "Projeto..." favoreceu a Alemanha como lugar propício para pesquisas psicológicas. Neste país, recém-unificado em 1870, a ciência incluía inúmeras áreas de conhecimento, desde fonética até arqueologia, entre outras, permitindo aos pesquisadores alemães aplicar seus estudos utilizando-se dos saberes de vários campos na pesquisa da vida mental. Segundo Schultz \& Schultz (1981), o início do século XIX foi seguido de uma onda de reformas educacionais nas universidades alemãs. Surgia um novo tipo de instituição, bastante diferente da clássica universidade européia, tendo como propósito principal a liberdade acadêmica e a pesquisa.

No centro dessa efervescência cultural encontrava-se Freud, que utilizou conceitos de várias áreas como medicina, biologia, filosofia e física de sua época para redigir o manuscrito de 1895 . Neste manuscrito apresenta um aparato neuronal fantástico, que ultrapassa a finalidade de promover uma psicologia como ciência natural, propósito que estampa os primeiros parágrafos do texto.

Tendo em vista essa finalidade, a posição tomada por Freud no "Projeto..." é a marca do Zeitgeist corrente na metade do século XIX, ou seja, um embate "entre as ciências do espírito ou morais (Geistwissenschaften), que visam compreender, e as ciências naturais (Naturwissenschaften), que procuram explicar" (Gabbi Jr., 2003, p. 19). Freud busca apresentar empiricamente o funcionamento da mente humana de acordo com uma descrição baseada, principalmente, na física de sua época. Embora suas elaborações transcendam o modelo neurológico corrente, e nem sempre fique restrito ao modelo científico esse ir além da "psicologia como uma ciência natural" faz com que o "Pro- 
jeto..." traga uma importante contribuição metapsicológica e contenha alguns gérmens de conceitos que serão retomados e desenvolvidos posteriormente.

O objetivo do presente artigo é apontar como a repetição, um dos conceitos de grande relevância para a psicanálise, já se encontra tematizado no "Projeto..." não como elaboração teórica, mas certamente como questão. Frente a isso visamos articular a figura da repetição com a vivência da dor, a memória e o $a$ posteriori. Buscamos ainda mostrar como o conceito de compulsão à repetição, introduzido em 1920, encontra-se numa relação próxima à vivência da dor, conforme apontam Caropreso \& Simanke (2006).

\section{Dor, memória e repetição}

No "Projeto...", de 1895, Freud postula um princípio fundamental e originário de toda atividade nervosa: o princípio de inércia, segundo o qual a tendência do aparato neuronal é libertar-se de toda excitação que lhe chega. "Um sistema nervoso primário se vale dessa quantidade adquirida para descarregá-la nos mecanismos musculares (...) desse modo fica livre de estímulos. Essa descarga representa a função primária do sistema" (p. 348). A esta função soma-se outra, função secundária, na qual o aparato procura conservar as vias de descarga que lhe permitem afastar-se das fontes de excitação. Haveria então, além da tentativa de livrar-se de toda excitação, uma fuga do estímulo.

Contudo, esta fuga não se dá com relação às estimulações endógenas das quais o organismo não pode se esquivar. Tais estímulos têm por características serem constantes e imperativos; são os motivos das grandes necessidades: fome, respiração e sexualidade. Estas necessidades são satisfeitas por meio de uma ação específica, e para realizá-la é preciso um refinamento no processo de descarga.

Nessa perspectiva os estímulos endógenos imporiam ao aparato neuronal a substituição do princípio de inércia pela tendência a manter a quantidade neuronal constante, em um nível mínimo necessário para a ação específica ser realizada. A estrutura do sistema neuronal elaborada por Freud teria como finalidade manter afastada a quantidade, enquanto sua função principal seria descarregá-la quando a constância da energia do aparato fosse alterada, buscando voltar sempre ao ponto de equilíbrio. Em outros termos manter a quantidade em um mínimo aceitável e constante, livre de oscilações, é a função do aparato como um todo.

O próximo passo de Freud é distinguir os sistemas de neurônios do "Projeto..." em permeáveis, chamados de phi $(\phi)$, os quais não retêm qualquer quantidade; e os neurônios impermeáveis, chamados psi $(\psi)$, que por sua vez retêm e 
são modificados com a passagem de certa quantidade. Com isso é destacada uma dimensão automática do funcionamento do aparato e do próprio humano, uma vez que a consciência não exerce influência direta sobre os dois sistemas neuronais onde ocorre grande parte dos processos psíquicos; a consciência será incluída em um terceiro sistema chamado ômega $(\omega)$, conforme veremos adiante.

A independência dos outros sistemas em relação à consciência marca a originalidade do pensamento freudiano (Pilão, 2009) frente à tradição cartesiana onde o eu e a consciência possuem um lugar central. A grande novidade do aparato no "Projeto..." se refere a processos que fogem ao alcance do eu, "Freud alarga a dimensão psíquica (...) ao apresentar o funcionamento mental marcado por um desconhecimento daquele de cuja mente falamos (...) anunciando a radicalidade do que está por vir com o advento (...) do inconsciente" (p. 18).

Os neurônios que podem ser ocupados, os $\psi$, levam Freud a supor que no ponto de contato entre eles existam resistências, as barreiras de contato. Essas barreiras são modificadas quando atravessadas por certa quantidade. Tal hipótese possibilita introduzir a noção de memória no "Projeto..." que, de acordo com Freud (1895[1950]), era essencial: “... uma teoria psicológica digna de consideração precisa fornecer uma explicação para a memória” (p. 351).

As barreiras de contato são descritas conforme o "grau de facilitação. Pode-se, então, dizer: a memória está representada pelas facilitações existentes entre os neurônios $\psi$ " (p. 352). Notemos que o grau de resistência existente nas barreiras de contato não são idênticos, pois se fossem não haveria necessidade de caminhos preferenciais a serem seguidos, conforme a exigência da função secundária, e da própria memória. "Por isso, pode-se dizer de maneira ainda mais correta que a memória está representada pelas diferenças nas facilitações entre os neurônios $\psi$ " (loc. cit.), ou seja, a memória se deve à capacidade do neurônio ser modificado pela passagem da excitação. É pela magnitude da impressão que a memória é, então, constituída, deixando um traço ou uma marca atrás de si nos neurônios psi $(\psi)$.

Cabe fazer uma distinção entre traço e um outro tipo de impressão chamado marca, utilizando as indicações referidas por Knobloch (1998). Distinguir esses dois conceitos é fazer referência à memória, pois as representações que serão "constitutivas do inconsciente não são senão traços mnemônicos investidos e protegidos pelo recalcamento" (p. 85), justamente porque os traços estariam sujeitos a um "rearranjo", usando o termo de Freud da Carta 52 (1896), na medida em que novas circunstâncias fossem agregadas à memória. Com isso fica destacada a importante tese de Freud de que a memória se desdobra em vários tempos, ou seja, ela pode sofrer retranscrições ou rearranjos dos traços que a compõem. 
Com relação a esta diferença entre traço e marca deve-se considerar que, para se transformar em um traço ou uma marca, é necessário antes de tudo que uma impressão tenha força suficiente para causar alguma sensação no psiquismo. $\mathrm{O}$ traço é impressão que será presentificada pela lembrança, ou seja, implica uma inscrição na cadeia de representantes, sendo capaz de associar-se a outros traços. Quanto à marca trata-se de um tipo de impressão que não participa da cadeia de representação, dessa forma não pode ser evocada como uma lembrança, "mas como fator energético. Não se trata, portanto, de representação, mas de expressão de pura intensidade" (Knobloch, 1998, p. 89) que será apresentada, e não representada, no aparato sob a forma de uma repetição desprazerosa a qual o eu não consegue fazer frente. Esta tese encontrará eco nas elaborações teóricas da virada de 1920 em "Além do princípio de prazer", mais especificamente com relação à compulsão à repetição das neuroses traumáticas.

Voltemos a atenção para essa primeira definição da memória que destaca as repetições de vias por meio das quais são eleitos os caminhos preferenciais, visando o melhor escoamento da quantidade. A facilitação depende da magnitude da quantidade que passa pelo neurônio e do número de vezes que esse processo acontece. Segundo Santos (2006) essas repetições irão criar um sistema de diferenças, fundamental para orientar as vias facilitadoras do escoamento da quantidade que chega ao aparato: essa é a função da memória.

Freud pensou o aparelho neuronal de maneira que as grandes quantidades externas estivessem afastadas de phi $(\phi)$ e, mais ainda, de psi $(\psi)$, devido ao escudo protetor dos órgãos dos sentidos que filtram a quantidade provinda do exterior, e pela conexão indireta de psi $(\psi)$ com o mundo externo. Contudo há um fenômeno que corresponde à falha destes dispositivos de proteção, uma vez que tais dispositivos têm um limite de eficiência: trata-se da dor.

A dor consiste em grandes quantidades de excitação veiculada pelos neurônios phi $(\phi)$ fazendo irrupção, sem a mediação do escudo protetor, nos neurônios psi $(\psi)$, que a recebe como se fosse atingido por uma grande descarga elétrica, tal a magnitude de sua força. Esta energia invasora desestabiliza a organização do aparato, deixando atrás de si facilitações permanentes em psi $(\psi)$. "A dor aciona tanto o sistema phi $(\phi)$ como o psi $(\psi)$, não há nenhum obstáculo à sua condução, e ela é o mais imperativo de todos os processos. Os neurônios psi (y) parecem, pois, permeáveis a ela" (Freud, 1895[1950], p. 359).

Na primeira parte do "Projeto...", o capítulo 6 é dedicado à questão da dor e o capítulo 12 à vivência de dor; entre esses dois capítulos Freud introduz o sistema neuronal responsável pela percepção-consciência: sistema ômega $(\omega)$. Tal sistema tem como função fornecer signos de qualidade à psi $(\psi)$; além da qualidade, exibe algo muito diferente: as sensações de prazer e desprazer. O despra- 
zer é identificado por um aumento da quantidade de excitação em psi $(\psi)$, já o prazer é identificado com descarga excitação.

Segundo Barbier (1999), nota-se a propósito da vivência de dor, uma elevação do nível quantitativo em ômega $(\omega)$, "uma tendência à descarga; e uma facilitação entre essa tendência e a imagem mnemônica do objeto que causou a dor" (p. 126; tradução nossa). Se a imagem do objeto hostil receber um novo investimento, irá produzir algo semelhante à dor: o desprazer, e junto a isso uma necessidade de descarga correspondente à dor já sentida previamente. Como há, consequentemente, um investimento na representação-lembrança do objeto hostil ocorre uma alucinação, e no lugar da dor surge o afeto, resíduo da vivência de dor.

A partir destes investimentos energéticos Freud procura, utilizando-se dos exemplos ocorridos na vivência de dor e de satisfação, não medir a quantidade, e sim exemplificar e entender como ocorre a descarga da excitação, e os efeitos que a passagem da quantidade provoca no aparato (Herzog, 2001). A respeito disso Freud, no Rascunho E (? junho de 1894), afirma que a angústia surge por transformação da tensão sexual acumulada; esse acúmulo se deve ao fato da descarga não ter sido realizada, e o represamento deste excesso tem como consequência a neurose de angústia; nesse sentido Freud considerou fundamental entender como o aparato neuronal é capaz de transmitir e transformar a energia que circula pelos neurônios, ou seja, compreender economicamente as forças nervosas.

Neste ponto são introduzidos dois conceitos que visam responder aos modos de condução da energia no aparato, e serão retomados na virada de 1920: o processo primário e o secundário. O processo primário é regido pelo princípio de inércia e diz respeito à forma de condução da energia que tende à descarga pela via mais facilitada sem sofrer inibição ou processamento; já no processo secundário há um retardamento da energia, ela sofre uma mediação por parte do eu para que o aparelho não invista, automaticamente, de forma muito intensa na representação-lembrança do objeto hostil, no caso da experiência de dor; e de desejo, no caso da experiência de satisfação.

Seguindo a indicação de Caropreso \& Simanke (2006, op. cit) notamos que a energia do processo primário tem a característica de livre mobilidade e poderia, deste modo, conduzir à reativação de representações que, mesmo em sua origem, produziram desprazer, o que ocorreria sobretudo nos processos derivados da dor. Para evitá-la é necessária a ligação, a partir do eu, dessa quantidade que irrompe em estado livre. Configura-se, aí, a função do eu: mediar a energia livre que irrompe no aparato.

É necessário que ocorra um trabalho sobre as excitações para que uma inscrição seja realizada, ou seja, é preciso uma dominação prévia destas energias para que elas possam ser inscritas como representações. Isso não ocorre com as mar- 
cas, que remetem para algo que escapa ao domínio do aparato, logo para fora do campo das representações, o que parece apontar para experiências não inscritas que ultrapassam a capacidade do aparato de dominá-las, persistindo como pura intensidade e aparecendo sob uma repetição compulsiva do evento doloroso.

A experiência de dor pode ser reativada tanto por uma percepção como por uma lembrança. Porém, o que é repetido, quando o objeto hostil é percebido ou lembrado, não é a dor, e sim um estado de desprazer: o afeto. De acordo com Aubert (1996) dor não é desprazer, mesmo partilhando com o afeto sua característica quantitativa. A repetição da experiência que envolveu a dor representa, a nível das lembranças, um desprazer emanando internamente, resultante da ação dos neurônios secretores que após receber uma excitação "engendram no interior do corpo alguma coisa que age como um estímulo sobre as vias endógenas de condução resultando em psi $(\psi)$ ” (p. 101; tradução nossa).

Nesse sentido Pontalis (2005) afirma que Freud opõe vivência da dor e vivência de satisfação. Assim, o par de opostos criados não é "como seria de se esperar prazer-desprazer, mas de um lado prazer-desprazer, e, por outro dor" (p. 267). A dor tal como é apresentada no "Projeto..." é diferente, portanto, do desprazer.

A dor produz essa qualidade especial, o afeto; esse estado inclui o desprazer e a tendência à descarga que correspondeu à experiência de dor. $\mathrm{O}$ afeto provoca no aparelho neuronal uma resposta automática: a defesa primária, que será repetida toda vez que surgir desprazer motivado pela reativação da experiência de dor, ou seja, as facilitações que conduzem ao desprazer deixam de ser percorridas. Com isso surge o eu: uma rede de neurônios bem facilitados entre si e constantemente investidos, que regula a passagem da quantidade no aparato.

O eu de 1895 é uma organização neuronal, que interfere na passagem da quantidade ocorrida de determinada forma, ou seja, acompanhada de dor ou satisfação. As primeiras ligações são denominadas sínteses passivas, elas colocam um limite ao livre escoamento da energia; em um segundo momento transformam-se em sínteses ativas, que atingirão excitações que já foram acompanhadas de "prazer ou dor e que se tornam elementos de uma repetição. O eu é o responsável pela repetição de experiências anteriores (experiências de satisfação) ou pela inibição da descarga" (Garcia-Roza, 1991, p. 151); o eu também procura livrar-se dos investimentos pelo método da satisfação, e, para tanto, conta com o auxílio dos neurônios ômega $(\omega)$ : esses neurônios fornecem a indicação de realidade, ou não, do objeto. Esta indicação se constitui como um fator determinante para os investimentos mediados pelo eu.

A inibição da quantidade realizada pelo eu permitirá um critério de diferenciação entre a percepção e a lembrança. A "aquisição biológica” (Freud, 
1895[1950], p. 425) ensinará, então, a não iniciar a descarga antes da chegada da indicação da realidade e, tendo essa finalidade em vista, não levar o investimento das lembranças além de certa quantidade, evitando, assim, a alucinação e o consequente desprazer.

A quantidade retida no eu pode ser empregada em investimentos laterais, com a finalidade de modificar o curso dos processos associativos e impedir aqueles que resultam em desprazer. O investimento lateral é uma inibição do livre escoamento da energia, alterando seu curso por meio de uma rede de neurônios bem facilitados e visando a descarga de uma maneira eficiente para o organismo.

Pelos investimentos laterais o eu consegue inibir a alucinação, a descarga motora e a ocupação da representação hostil, evitando o aumento da magnitude da excitação. "Tudo que chamo de aquisição biológica do sistema nervoso é, na minha opinião, representado por uma ameaça de desprazer dessa espécie cujo efeito consiste no fato de não serem investidos os neurônios que levam a liberação de desprazer" (ibid., p. 426). Isto constitui a defesa primária, ou seja, os caminhos que conduzem ao desprazer devem ser evitados.

Devido a dificuldade em explicar como a defesa primária pode ser representada mecanicamente, Freud lança mão do mecanismo da atenção, que irá regular os deslocamentos dos investimentos realizados pelo eu. Há, portanto, uma segunda regra biológica, a da atenção: essa regra enuncia que o eu tem uma tendência a ocupar redes neuronais onde ocorrem os processos originados na recepção de estímulos externos. O eu "quase sempre tem investimentos intencionais ou de desejo, cuja presença durante a investigação influencia a passagem da associação, produzindo um falso conhecimento das percepções" (ibid., p. 429).

De acordo com Freud, mesmo depois de percepções desprazerosas tornarem-se imagens mnêmicas, é constatado que suas repetições continuam a despertar afeto, "até que, com o correr do tempo, percam essa capacidade" (ibid., p. 436). O domínio pelo ego, dos processos primários resultantes de uma vivência de dor é muito mais difícil de ser alcançado. Só com repetidas tentativas seria possível subjugá-los, enquanto isso tais lembranças permanecem - seguindo a expressão usada por Freud - "indomadas" (loc. cit.)

É evidente que algo acontece no curso das repetições desprazerosas que aos poucos provoca a inibição de tais lembranças. Tal domínio do ego é mais demorado nos casos de lembranças capazes de gerar afetos, pois traços de experiência de dor foram investidos com quantidade proveniente de phi $(\phi)$ excessivamente intensa, sendo propícia para a liberação de desprazer.

Contudo, isso ocorre gradualmente: justamente devido às grandes quantidades presentes na vivência de dor, o eu aprenderia a não ocupar a representação do objeto hostil de maneira tão intensa toda vez que ocorresse um aumento de excitação. Tais representações deverão receber do eu uma ligação especialmente 
considerável e repetida para poder evitar essa facilitação para o desprazer. De acordo com o que foi considerado:

Encontra-se admitido, portanto, no "Projeto...", a hipótese de que há processos primários no aparelho que fazem retornar representações que, mesmo em sua origem, foram desprazerosas. Dito de outro modo, há nesse texto, claramente formulado, a ideia de um processo repetitivo que continua ocorrendo enquanto as representações ainda não foram ligadas. (Caropreso \& Simanke, 2006, p. 213)

\section{O tempo da repetição}

A experiência da dor ainda levanta outra questão relevante para o tema da repetição: a temporalidade. $\mathrm{O}$ afeto proveniente da reativação da lembrança do objeto hostil conduz a uma experiência de desprazer, diferente, portanto, da experiência de dor original. Pesquisando sobre a histeria, Freud constata que essa experiência é constituída em dois momentos ou tempos diferentes. Esses dois tempos "se sobrepõem na produção do trauma não sendo percebidos como distintos. O sintoma realiza essa condensação temporal de algo que se repetiu" (Santos, 2002, p. 31).

Na segunda parte do "Projeto..." ao tratar do Próton Pseudos na histeria Freud descreve um caso clínico, intitulado Caso Emma, que se desenrola em duas cenas: há um primeiro tempo, silencioso, que é evocado somente num segundo momento da terapia. No primeiro tempo, que Freud designa como cena II, Emma, com oito anos de idade, encontra-se sozinha em uma loja de doces, o confeiteiro toca seus órgãos genitais por cima de seu vestido e sorri.

A cena I, ocorrida quando Emma tinha 12 anos, provoca uma fobia que a impede de entrar sozinha em lojas; essa cena é relatada na clínica como o evento responsável pelo sintoma. Nessa cena, ao entrar desacompanhada em uma loja repara que dois vendedores estavam rindo; frente a essa situação Emma foge tomada por um crescente desprazer.

Durante o tratamento analítico a cena II, mais antiga que a cena I, vai ser trazida à luz. O riso dos vendedores evocou o riso do confeiteiro da cena II e o fato de também aí se encontrar sozinha. Com essa lembrança veio outra, a do abuso que agora, na puberdade, ganhava significado sexual, se transformando em afeto de angústia, devido ao temor de que os vendedores pudessem repetir o abuso. As duas vivências foram condensadas em uma só.

Nesse período Freud estava às voltas com a teoria da sedução, com a qual procurava solucionar o mistério dos sintomas apresentados na histeria. Tal teoria baseava-se na concepção de que o indivíduo sofria uma irritação real nos ór- 
gãos genitais durante a infância, o abuso ficava gravado na memória como um corpo estranho ao sujeito, e não como um evento traumático devido à imaturidade sexual da criança. Cabe lembrar que nesta época ele ainda não dispunha do conceito de sexualidade infantil.

Somente após o advento da puberdade tais lembranças adquirem um valor de trauma, ou seja, não são as próprias experiências que agem traumaticamente, e sim sua reminiscência. Reviver como recordação, após a maturidade sexual, o abuso experienciado passivamente conferia o valor de trauma à histeria. As lembranças vividas como experiência na infância ganham outra significação: pela retranscrição na memória, elas adquirem um valor traumático.

Nesse sentido podemos referenciar um modelo de temporalidade que toca a questão da repetição. Knobloch (1998) chama atenção para uma temporalidade que não a do acontecimento, pois é preciso o ganho de sentido sexual por meio da puberdade, ou seja, é no a posteriori que o efeito traumático irá ser produzido e não na experiência original, vivida na infância. Assim uma cena do passado é compreendida no presente, constituindo-se, assim, uma confusão temporal: é como se este passado não pudesse passar.

Na puberdade, o segundo tempo do trauma, as barreiras morais, conforme esclarecem Carvalho \& Ribeiro (2006), foram erigidas de tal maneira que as lembranças, ao serem despertadas, sofrerão uma repulsa do eu e serão recalcadas.

Em meados de 1897 Freud descarta essa explicação, abandonando a teoria da sedução, passando a considerar que estes abusos sofridos na infância e contados por seus pacientes não correspondiam necessariamente à realidade, tendo sido, na maioria dos casos, fantasiados. Desta forma, Lejarraga (1996) pontua que a fantasia ganha um lugar de maior destaque na produção das neuroses, ou seja, a realidade factual cede lugar a um fator interno. A "realidade objetiva da cena traumática é substituída pela realidade psíquica dos desejos e fantasias inconscientes" (p. 21).

$\mathrm{O}$ aparato neuronal pode comportar o registro do abuso sexual, mas sem compreendê-lo, como se fosse um corpo estranho. São registros mantidos fora dos investimentos do eu, portanto, indomados, uma vez que não foram submetidos ao processo secundário. E por se tratar de lembranças que envolvem a sexualidade são carregadas de intensidade especial.

Na terceira parte do "Projeto..." (1895[1950]), Freud ressalta que o rememorar envolve um processo de pensamento regressivo, "retrocedendo, possivelmente até uma percepção" (p. 435), sendo que o pensamento pode "levar ao desprazer" (loc. cit.) se nesse curso regressivo esbarrar em lembranças ainda indomadas. São justamente essas lembranças não compreendidas, de ordem sexual, que se tornarão patogênicas ou traumáticas a posteriori. 
Para essas ocasiões o aparato conta com uma defesa especial: a defesa patológica ou recalcamento. Na carta 52 (1896/1996), Freud indica que a defesa patológica ocorre contra um "traço de memória de uma fase anterior, que ainda não foi traduzido" (p. 283). Nos casos de ordem sexual há um crescente desprazer porque as magnitudes das excitações causadas pelo abuso aumentam ou ganham mais força com o tempo, devido ao desenvolvimento sexual do indivíduo. Nesta lógica um evento sexual anterior (na infância) atua sobre a fase seguinte (da maturação sexual) como se fosse atual; o fato que determina o recalcamento, portanto, "é a natureza sexual do evento e sua ocorrência numa fase anterior" (p. 284).

No rascunho K, redigido em janeiro de 1896, Freud é taxativo quanto a essas ideias, apontando que basta a puberdade se colocar entre a vivência factual do abuso e sua repetição na lembrança, para que o trauma seja desencadeado. E conclui: “... para que a pessoa esteja livre da neurose, a precondição necessária é que antes da puberdade não tenha ocorrido nenhuma estimulação sexual de maior significação" (p. 268).

O recalcamento será um meio de evitar que as lembranças carregadas de afeto produzam desprazer, retirando seu investimento e deslocando-o para outras representações que tenham uma ligação fortuita com o evento de ordem sexual. Toda vez que algo relacionado ao trauma for evocado, a lembrança fortuita irá aparecer no lugar da experiência sexual traumática. Contudo, a defesa patológica não anula o poder patogênico da lembrança traumática, apenas a enfraquece deslocando sua energia.

"Porém, só se pode fugir de uma representação para outra, nisso consiste a formação do sintoma" (Santos, 2006, p. 36). Por esse motivo Freud conclui que toda compulsão corresponde a um recalcamento, e como neste processo há deslocamento da energia de uma representação para outra, toda emergência na consciência da representação traumática corresponde a uma amnésia. Há, portanto, um processo repetitivo iniciado com o recalcamento que faz parte do funcionamento do aparato neuronal; e visa evitar o investimento em representações que são penosas para o eu.

O a posteriori implica a repetição; a esse respeito Gondar (1995) salienta não ser preciso ocorrer uma reprodução exata para haver enlace entre duas representações. Basta que existam traços comuns a ambas; porém é necessário que essa repetição insira um novo elemento, capaz de conferir à primeira recordação um sentido que não lhe havia sido dado. Uma experiência fortuita vivida após a puberdade desencadearia a produção sintomática, o trauma, não é, portanto, produzido no passado, mas por meio do enlace entre duas representações dadas em tempos diferentes. 
Por estes processos que envolvem a representação-lembrança, sobretudo na experiência de dor, "a psicanálise pode suspeitar da existência de uma força que, enquanto silenciosa, foge à detecção, mas cuja potência pode ser inferida a partir dos efeitos que produz" (p. 83). Os estímulos endógenos, originados nas "células do corpo" e criadores das grandes necessidades, são os precursores do que será chamado de pulsão; estes estímulos têm por característica organizar-se em torno de um objeto utilizado para obter satisfação por meio da descarga da excitação. Como essas estimulações não cessam sua atividade, uma vez realizada a descarga, o processo recomeça, denotando um processo repetitivo que está no cerne do conceito de pulsão.

A dor, dentro da perspectiva apresentada no "Projeto...", de 1895, aparece como uma falha dos dispositivos de proteção do aparato, e aponta para um processo que mesmo envolvendo o desprazer continua se repetindo, trata-se de um mecanismo que se encontra fora do princípio do prazer e aponta para a compulsão à repetição (Caropreso \& Simanke, 2006).

Somente em 1920, no texto "Além do princípio do prazer", a questão da dor é retomada por Freud, numa concepção muito próxima do "Projeto...", mas certamente em outro nível de sua elaboração conceitual. Ela se caracteriza por uma ruptura no escudo protetor contraestímulos, que protege o aparato das excitações. Diante da ruptura do paraexcitação o aparato é inundado por um excesso pulsional, que coloca de lado o funcionamento do princípio do prazer, para realizar uma tarefa mais fundamental: dominar a excitação excessiva.

Toda vez que ocorre uma falha na tarefa de dominar a excitação, inicia-se um processo repetitivo que não envolve nenhuma possibilidade de prazer, processo denominado compulsão à repetição. Conceito que coloca Freud na trilha da pulsão de morte, e o leva a reformular o dualismo pulsional e, consequentemente, a segunda tópica.

\section{Referências}

Aubert, A. La douleur. Originalité d'une théorie freudienne. Paris: PUF, 1996. Barbier, A. Douleur muette, douleur criée, douleur parlée. Revue Française de Psychosomatique - "Douleurs", Paris, n. 15, 1999, p. 125-147.

CARopreso, F.; Simanke, R.T. Compulsão à repetição: um retorno às origens da metapsicologia freudiana. Agora, Rio de Janeiro, v. IX, n. 2, jul./dez.2006.

Carvalho, M.T. de M.; Ribeiro, P. de C. Modelos do trauma em Freud e suas repercussões na psicanálise pós-freudiana. Revista Percurso, São Paulo, n. $37,2^{\circ}$ semestre de 2006. 
Freud, S. Edição Standard Brasileira das Obras Psicológicas Completas de Sigmund Freud. Rio de Janeiro: Imago, 1996. 24 v.

. (1895[1950]). Projeto para uma psicologia científica. In: Edição Standard Brasileira das Obras Psicológicas Completas de Sigmund Freud. Rio de Janeiro: Imago, 1996. V. I, p. 335-454.

. (1893-1895). Estudos sobre a histeria. In: Edição Standard Brasileira das Obras Psicológicas Completas de Sigmund Freud. Rio de Janeiro: Imago, 1996. V. II. (? junho de 1894). Rascunho E. Como se origina a angústia. In: Edição Standard Brasileira das Obras Psicológicas Completas de Sigmund Freud. Rio de Janeiro: Imago, 1996. V. I, p. 235-240.

. (1896). Rascunho K. As neuropsicoses de defesa (Um conto de fadas natalino). In: Edição Standard Brasileira das Obras Psicológicas Completas de Sigmund Freud. Rio de Janeiro: Imago, 1996. V. I, p. 267-275.

. (1896). Carta 52. In: Edição Standard Brasileira das Obras Psicológicas Completas de Sigmund Freud. Rio de Janeiro: Imago, 1996. V. I, p. 281-287.

GABвi Jr., O.F. Notas a projeto de uma psicologia - As origens utilitaristas da psicanálise. Rio de Janeiro: Imago, 2003.

GARCiA-Roza, L.A. Introdução à metapsicologia freudiana - Sobre as afasias: o projeto de 1985. Rio de Janeiro: Zahar, 1991.

GonDar, Jô. Os tempos de Freud. Rio de Janeiro: Revinter, 1995.

Herzog, R. As duas faces do desejo. In: O estranho na clínica psicanalítica. Rio de Janeiro: Contra Capa Livraria, 2001. p. 27-41.

Knobloch, F. O tempo do traumático. São Paulo: Educ, 1998.

Lejarraga, A.L. O trauma e seus destinos. Rio de Janeiro: Revinter, 1996.

PILÃo, A.C. O sujeito freudiano em busca da felicidade. 2009. Dissertação (mestrado em Teoria Psicanalítica). Universidade Federal do Rio de Janeiro - UFRJ, Rio de Janeiro, 2009.

Pontalis, J-B. Entre o sonho e a dor. São Paulo: Ideias \& Letras, 2005.

SAntos, L.G. dos. O conceito de repetição em Freud. São Paulo: Escuta; Belo Horizonte: Fumec, 2002.

Schultz, D.P.; Schultz, S.E. História da psicologia moderna. São Paulo: Cultrix, 1981.

\section{Resumos}

(Repetition and the Project of 1895: seeds of a concept)

This article discusses the question of repetition in Freudian theory. Beginning with pre-psychoanalytic texts, we go back to the concept of the experience of pain, 
which confronts us with the problem of the repetition of displeasure. Pain appears as a failure of protective mechanisms of the neuronal apparatus and indicates the existence of a process that, despite involving displeasure, continues to be repeated. The process also provides indications of the concept that, twenty years later, Freud called compulsion to repetition.

Key words: Experience of pain, repetition, temporality, memory

(La répétition et le Projet 1895: les semences d'un concept)

Cet article vise à apporter une contribution à la question de la répétition dans la théorie freudienne. En partant de textes pré-psychanalytiques, nous proposons reprendre le concept du phénomène de la douleur, ce qui nous met face au problème de la répétition du déplaisir. La douleur apparaît comme un échec des dispositifs de protection de l'appareil neuronal, indiquant un procédé qui, même en impliquant le déplaisir, se répète en permanence et nous fournit des indices de ce qui, vingt ans plus tard, sera nommé compulsion de répétition.

Mots clés: Phénomène de douleur, répétition, temporalité, mémoire

(La repetición y el Proyecto de 1895: semilla de un concepto)

Este artículo objetiva contribuir sobre la cuestión de la repetición en la teoría freudiana. Se propone partir de los textos pré-psicoanalíticos para rescatar la vivencia del dolor, concepto que nos coloca frente al problema de la repetición del desplacer. El dolor aparece como una falla de los dispositivos de protección del aparato neuronal, señalando hacia un proceso que, aunque envuelva al desplacer, continua repitiéndose, lo que nos da indicios de lo que, veinte años después, será denominado como compulsión a la repetición.

Palabras clave: Vivencia del dolor, repetición, temporalidad, memoria

Citação/Citation: Antonello, D.F.; Oliveira, R.H. DE. A repetição e o "Projeto..." de 1895: gérmen de um conceito. Revista Latinoamericana de Psicopatologia Fundamental, São Paulo, v. 14, n. 2, p. 237-251, jun.2011.

Editor do artigo/Editor: Prof. Dr. Manoel Tosta Berlinck

Recebido/Received: $13.5 .2010 / 5.13 .2010 \quad$ Aceito/Accepted: $20.9 .2010 / 9.20 .2010$

Copyright: @ 2009 Associação Universitária de Pesquisa em Psicopatologia Fundamental/ University Association for Research in Fundamental Psychopathology. Este é um artigo de li- 
vre acesso, que permite uso irrestrito, distribuição e reprodução em qualquer meio, desde que o autor e a fonte sejam citados/This is an open-access article, which permits unrestricted use, distribution, and reproduction in any medium, provided the original author and source are credited.

Financiamento/Funding: Esta pesquisa é financiada pela CAPES - Coordenação de Aperfeiçoamento de Pessoal de Nível Superior e pelo Conselho Nacional de Desenvolvimento Científico e Tecnológico - CNPq/This research is funded by the CAPES - Coordenação de Aperfeiçoamento de Pessoal de Nível Superior and by the National Counsel of Technological and Scientific Development - CNPq

Conflito de interesses/Conflict of interest: Os autores declaram que não há conflito de interesses/The authors declare that has no conflict of interest.

\section{Diego Frichs Antonello}

Psicólogo; Mestrando em Teoria Psicanalítica pelo Programa de Pós-Graduação em Teoria Psicanalítica da Universidade Federal do Rio de Janeiro - UFRJ (Rio de Janeiro, RJ. Brasil); Bolsista de Mestrado da CAPES - Coordenação de Aperfeiçoamento de Pessoal de Nível Superior (Brasília, DF, Brasil).

Rua Paulino Fernandes, 10/13 - Botafogo

22270-050 Rio de Janeiro, RJ, Brasil

Fone: (21) 3281-8819

e-mail: dfantonello@yahoo.com.br

\section{Regina Herzog de Oliveira}

Psicanalista; Professora associada do Programa de Pós-Graduação em Teoria Psicanalítica da Universidade Federal do Rio de Janeiro - UFRJ (Rio de Janeiro, RJ. Brasil); Pesquisadora do Conselho Nacional de Desenvolvimento Científico e Tecnológico - CNPq (Brasília, DF, Brasil).

Rua Almirante Guillobel, 37/202 - Lagoa

22471-150 Rio de Janeiro, RJ, Brasil

Fone: (21) 8132-8507

e-mail: rherzog@globo.com 